\title{
A METHOD FOR MEASURING MUSCULAR GROUP “CONTROL-ABILITY" AND ITS APPARATUS
}

\author{
Tetsuo MESHIZUKA, Ph.D., and Akira NAGATA \\ Physical Fitness Laboratory, Faculty of Science, \\ Tokyo Metropolitan University
}

\section{Introduction}

It is a well-known fact that the various muscular movement as one of the human body functions is essential for physical fitness and these movements have been observed in various experimental studies. The muscular movement research as a basic academic area for physical education through the fundamental kinetic method on human movements should play increasingly more important part.

The purposes of the study were (1) to establish the method for measuring the controlability which has never been disignated clearly before, (2) to find out the suitable method for calculating the muscular components quantitatively, and (3) to prepare the apparatus of the motor control amplifier by which three mechanical loads will be manufactured continuously.

The "control-ability" in the limb muscular movement has been thought to be the main part for regulation of physical activities, but its evaluative method to calculate the quantity of regulative elements, which constitute of three components; elasticity, viscosity and mass inertia, have not been developed yet.

The dynamic properties of muscle contraction and its neural control were successfully carried on by numerous physiologists ${ }^{8)}$, who mostly performed on animals appling the isometric contraction.

In our method, the living upper-extremity was used in the examination, to which a special-control device was attached with the greater power relative to that of the muscle.

The neuromuscular control response was recorded as a variance of the directed control values which are also called "error variables".

This type of stimulus has been found to be convenient in order to evaluate the characteristics; (a) of muscle properties, (b) of muscle control-ability, and (c) of the myotatic reflex. This sort of study on the limb control movement should be carefully followed up further in future.

The device also was utilized in man to calculate his pursuit or tracking capability as the human operator, and to compare the normal human power with the given power on the apparatus. An essential part of this device was that the lengthening of the muscular group could be recorded when the amplitude in voltage between the external force applied and the force in kilogram exerted by the muscle differed.

In this paper the limb muscle contractions are dealt with. for the existing methods and instruments seem to be lacking mechanical accuracy and qualitative measurements. Consi- 
dering the defects involved in the existing methods for the neuromuscular control capacity of man, a new apparatus to measure more accurately and more quantitively has been developed by the authors, which proved to well-stand to elaborate measurements of muscular control.

\section{Review of Literature}

A. V. Hill 1) and D. R. Wilkie ${ }^{2)}$, in their earlier studies, put the emphasis on the use of transient force stimulus or isotonic shortening, and brought out the formula of the muscle contraction speed and force. By R. O. Granit ${ }^{3)}$ in 1959, it was demonstrated that whether force as a mechanical variable was processed and controlled by the central nervous system, although this is still subject to controversy, except that some muscle receptors; such as Golgi tendon organ and muscle spindle, are highly sensitive to force and length during active contraction. In their previous studies, J. Massion 4) and P. B. C. Matthews ${ }^{5)}$ have shown that when the sinusoidal wave force was applied to the flexors of the forearm in man, a striking oscillation of the limb occurred, even when the subject tried to maintain his forearm in a fixed position. The result of their studies revealed the complication of the muscle control-abiltiy using the displacement input in man, which had not ever been foreseen then.

J. C. Houk ${ }^{6)}$ and others developed the mechanical muscle model and evaluated the muscular control movement of length and force feedback to soleus muscle.

Also, L. S. Stark 7) indicated in his bioengineering study, that the neuro-muscular control system could be established. These observations have motivated us to conduct a more systematic study to obtain much data in control movements in man.

\section{Qualities Essential for the Motor Control}

We must not fail to notice that such study as ours on the control theory should influence upon the activity in physical education as a basic science. In other words, peripheral motion of mankind is fedback into his central nervous system and the whole system is closed, that is the elevation of the load stimulus produces the increase of the impulse of the muscular receptors, the connection between the command stimulus and the responses of the muscular effectors corresponds to a negative feedback loop. In the scheme shown in Figures 1(a) and (b), the controlled quantity (movement of forearm) is directly fed back into the input of controlling system (central nervous system, visual system and myotatic system). When the gain of feedback loop is equal to 1 , this system corresponds to the real regulatory system. On the contrary, when the gain is equal to 0 , the system corresponds to an open loop system. Thus, control system may be altered by changing the loop gain. Considering the relationship between the stability of the

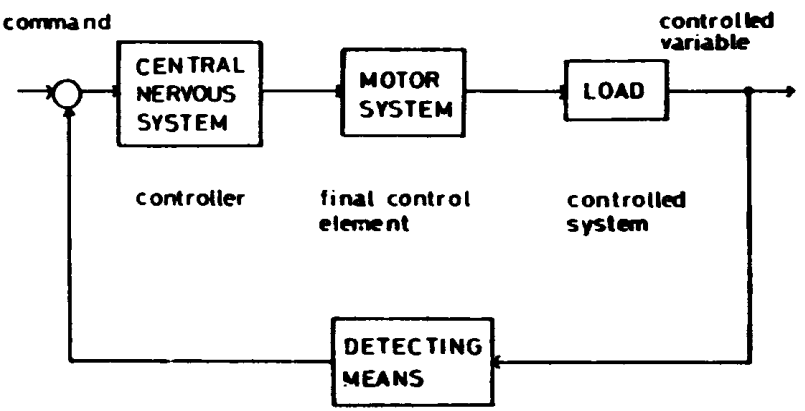

Fig. 1. (a) The block diagram of the control in the muscular movement. 


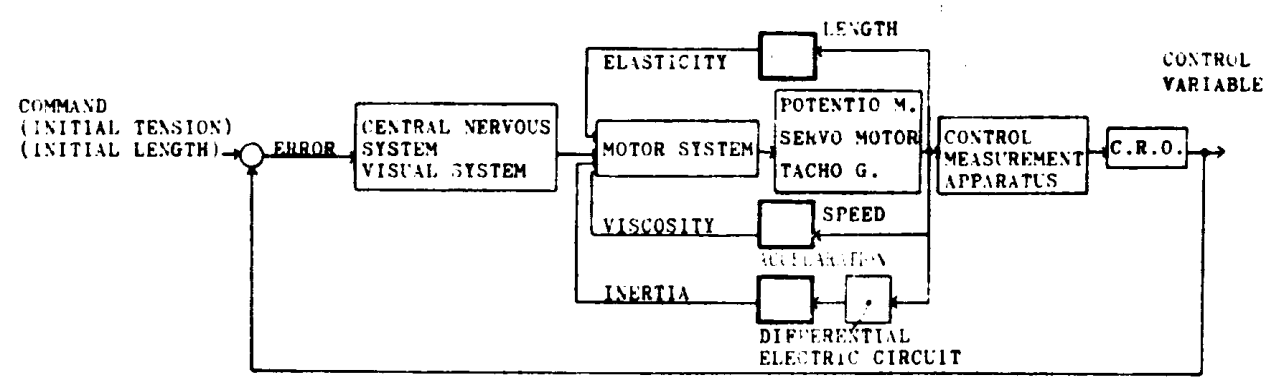

Fig. 1. (b) The block diagram of the control in the muscular movement.

load stimulus (dynamic forces) and the controlled variables (movement of forearm), we can analyze the mechanism of the human control system.

In order to obtain the highest reliability and accuracy of the muscular controlled movements, three contractile elements in the skeletal muscle; elasticity element, viscosity resistance and mass inertia, which are contributive to "two-element theory" 2), are the same as the load stimulus for the forearm movement. Figure 2 shows the presumed model of the muscle by the authors.

This mechanism of the muscle is so simple that resistance exerted is transferred into three physical volume dimensions which are developed to fit into the load stimulus, and this simulation can be registered on the electric computer (analog computer) and demonstrated in the examination of the living muscle (Rana catesbiana).

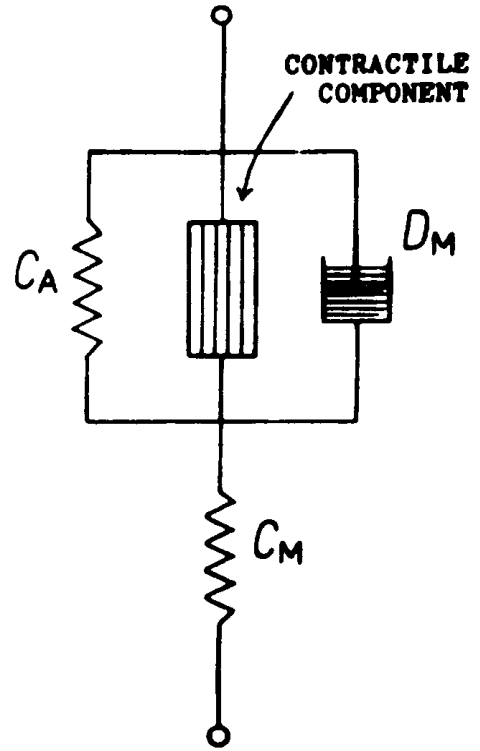

Fig. 2. A model of muscle C A : parallel compliance $\mathrm{CM}$ : series compliance DM : damping coefficient

\section{Methodology}

An apparatus named "Load Control Amplifier" was constructed by the authors. Using this apparatus, the mechanism of motor control-ability by a muscle group has been studied.

A variable force was applied to the wrist of a seated subject whose upper arm held horizontal and perpendicular to the transverse plane of the shoulders. The scheme of the experiments is shown in Figure 3. The forearm was free to rotate around the elbow and the wrist was in a semiprone position. The subject was given various kinds of load waves as the command of controlling and was subjected to follow up this variation of waves which were generated by the electric oscillator. The instruction to keep his forearm vertical was given against the external force applied to it. The beam in the CRO (Cathod Ray Oscillograph) gives the subject an indication of his forearm position. The other beam showes the controlled value of his forearm, and the error variable between the command value and the manipulated value is displayed in the record sheet, which distribute the fundamental data for estimation of the human control-ability. 
The input force was applied by means of an electrically rotated wheel of servo-motor (shown in Figure 4) controlled by the electric circuit of the authors' apparatus which is shown in Figure 5.

This electric circuit for the load control amplifier enables to change the load freely from low to heavy as well as rapid electric changes with high stability. As shown in Figure 6, initial torque generated by the electric source, is given to the wheel to rotate the subject's forearm.

The electric powcr to rotate the axes of the wheel or the servo-motor is amplified by 6RP electric vacuum tube and is delivered to the control terminal of the servomotor, which is excited by the alternative current.

Among the applied forces, (1) the elasticity resistance is sent to the input of screen grid, which is delivered to $\mathrm{CH}$ (chopper converter-DC to $\mathrm{AC}$ ).

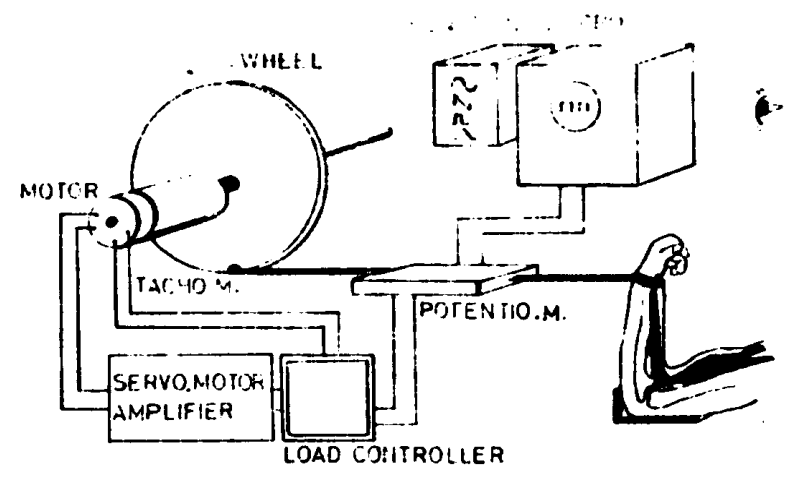

Fig. 3. The scheme of the experiment for control movement.

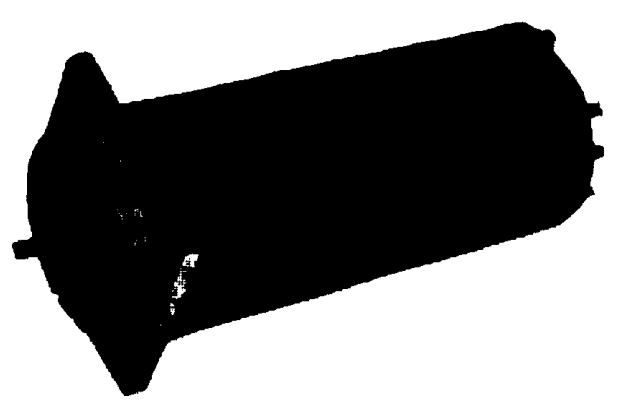

Fig. 4. The photograph of the servomotor utilized in the experiment.

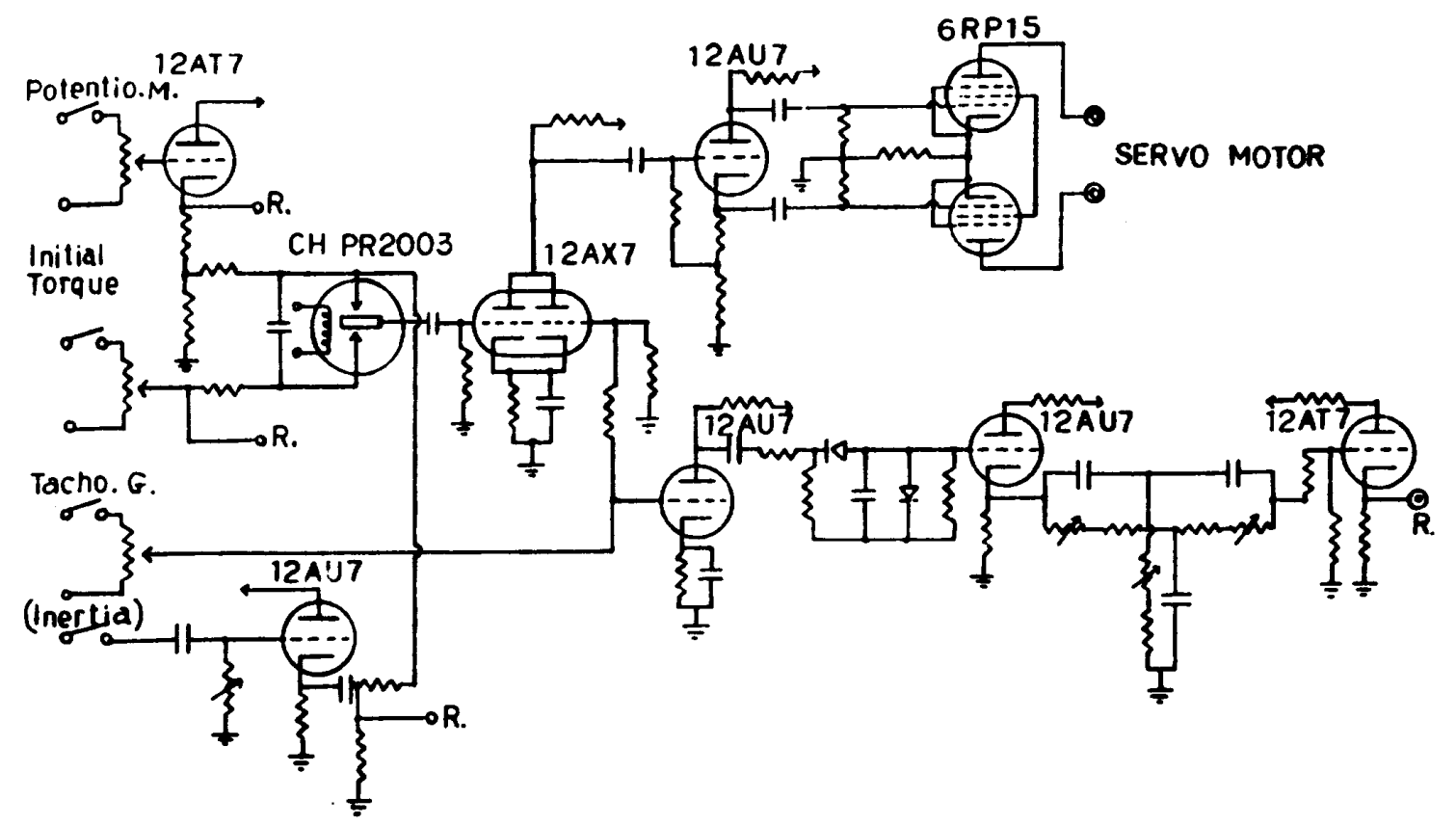

Fig. 5. The electric circuit for controlling the servo-motor. 


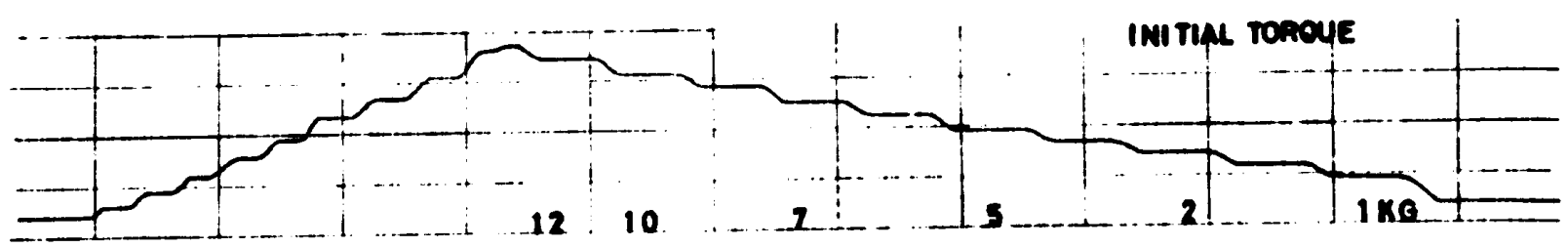

Fig. 6. The variation of initial tor ue.

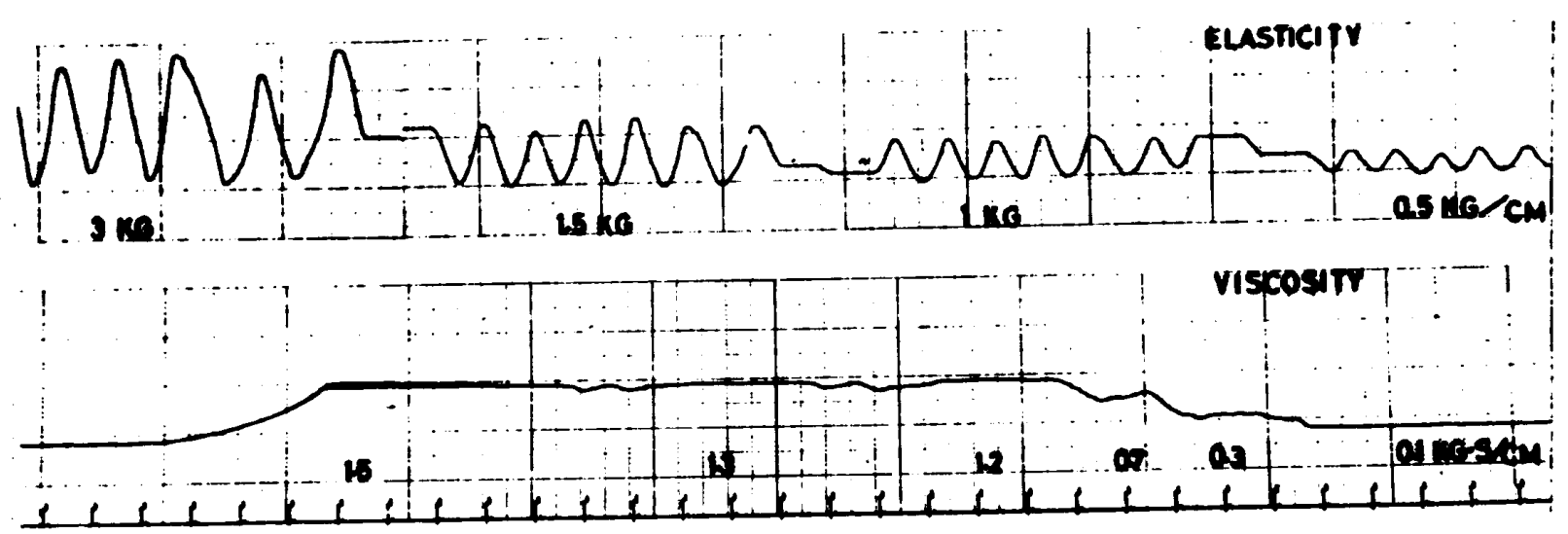

Fig. 7. The record of elasticity and viscosity of the muscle or of the external load.

Table 1. The detecting means ane load

\begin{tabular}{lll}
\hline & \multicolumn{1}{c}{ DETECTING MEANS } & \multicolumn{1}{c}{ LOAD } \\
\hline DISPLACEMENT & linear potentiometer & ELASTICITY \\
\hline VELOCITY & tacho meter & VISCOSITY \\
\hline ACCELARATION & differential electric circuit & INERTIA \\
\hline
\end{tabular}

As shown in Figure 7, (2) the viscosity resistance also is produced through speed volumes, which are fed back to servomotor in the reverse direction. The speed of the wheel is chased by a tacho-meter attached to the side of the motor. The third force, mass inertia is manufactured by the integrated electric circuit. The applied forces mentioned above are recorded by the detecting method as shown in Table 1 .

\section{The Muscular Movement in the Experiment}

The muscles involved in the test were the forearm flexors and extensors. The activities that would involve brachioradialis, biceps brachii, and triceps muscles were given to the subject. As the forearm was positioned with an angle of 90 degrees to the upper arm, and the movements recorded were quite fast and performed in opposition to the force, the brachioradialis muscle was particularly active compared with other flexors, hence measurements were mostly made. In future, the muscular movements should be recorded by means of needle electrodes. 


\section{Results of Examination}

1) Initial conditions given to the apparatus :

The sinusoidal stimulation used as the command of control movement was mainly applied to make analysis of the neuromuscular control system. The error values was used mainly (1) to estimate the muscular control-ability, (2) to provide the successive loading and unloading, and (3) to study the dependence of muscular response to the varied forces applied. A fixed frequency wave $(0-5 \mathrm{~Hz})$ was applied to rise the muscular responses as the first parameter and the initial torque or force-amplitude were fixed as the second parameter in order to obtain certain indications assuring linearity of the response (Figure 6). These parameters were fixed to be smaller compared with the maximum isometric force of the forearm flexors.

To investigate the frequency effects, the oscillation-level of the function-generator was also fixed so as to induce a peak-to-peak wave. The command variables were established to correspond to the frequency level ranging from 0 to $5 \mathrm{~Hz}$, which is presumed possible to be tracked by human limb (Figure 8 ).

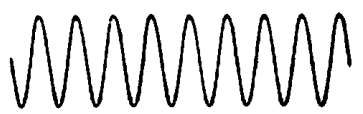

$1.2 \mathrm{HT}$
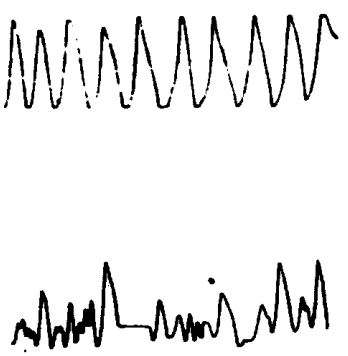

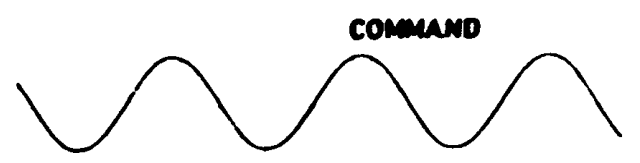

$0.3 \mathrm{~Hz}$

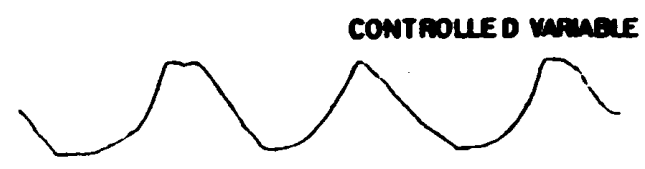

ERAOR - - . - . .

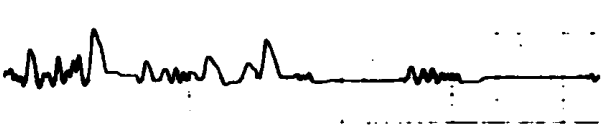

Fig. 8. The record of frequency level (command), controlled variable and error value.

2) Force-loading to the apparatus:

For the purpose of seeking for (1) the control-ability of man, (2) the muscle constitution, the elasticity and viscosity, varied resistances were applied into the loading force. If each component of the muscle should correspond to the external loads applied, the properties of muscle can be examined (Figure 9). Despite the spontaneous oscillation of the limb was relatively small and sometimes observed at certain frequency, subject's effort to maintain his position suggested an effort to mobilize his flexors and his effort appeared as a phase in the oscillograph as a displacement value. All the said loads are shown in Figures 7-9.

When the frequency of the load wave was increased, the wrist displacement was increased in both cases when subject's eyes were open and closed. 


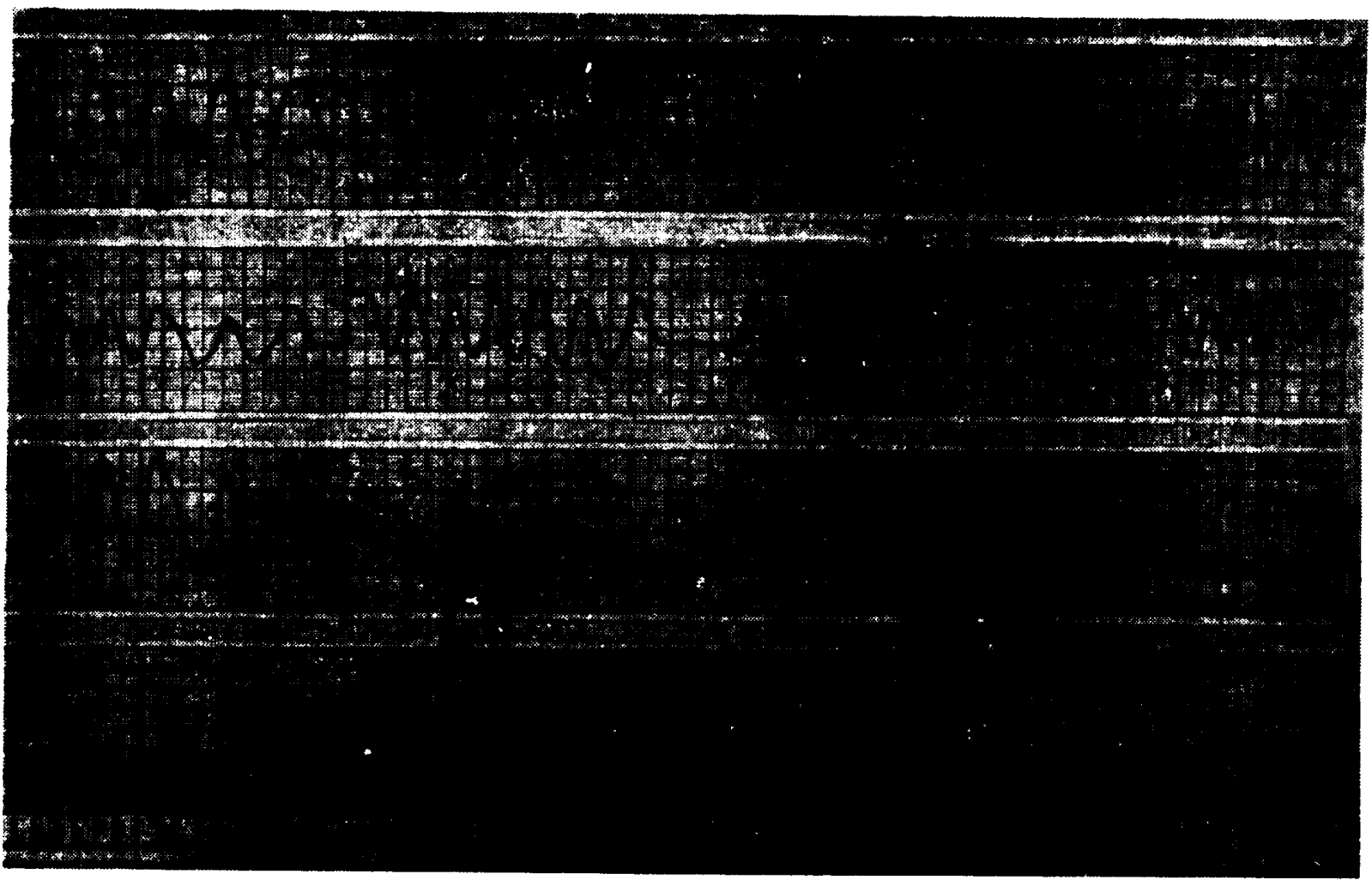

Fig. 9. Sample redords of the experiments.

The problems remained in this device seem to be (1) how to minimize the external inertia; mechanical and muscular, and (2) how to induce the muscular components through the apparatus.

Note: The authors' gratitude should be mentioned toward Professor I. Hatakeyama, without whose academic supports and his constant encouragement, our efforts might have been less useful. It is our will to continue this work further in future.

\section{Reference}

1) Hill, A.V.: The effect of series compliance on the tension developed in a muscle twitch. Proc. Roy. Soc., Ser. B, 138: 325-329, London, 1951.

2) Wilkie, D.R.: The relation between force and velocity in human muscle. J. Physiol., 110: 249280, London, 1950.

3) Granit, R., Pompliano, O., and Waltman, B.: The early discharge of mammalian muscle spindles at oneset of contractiun. J. Physiol., $147: 399-418$, London, 1959.

4) Massion, J.: Role possible de lactivite rythmique du noyau ventrolatral dans la predetermination centrale du movement. J. Physiol., $60: 497-498$, Paris, 1959.

5) Matthews, P.B.C.: The reflex excitation of the soleus muscle of the decerebrate cat caused by vibration applied to its tendon. J. Physiol., 184: 450-472, London, 1966.

6) Houk, J.H., Singer, J.J. and Goldman, M.R.: An evaluation of length and force feedback to soleus musle of decerebrate cats. J. Neurophysiol., 38(6): 784-811, Boston, 1970.

7) Stark, L.S.: Neurological feedback control system. Advances in Bioengineering and Instrumentation, 289-385, New york, 1966.

8) Lippold, O.C.J., Redfearm, J.W.T. and Vuco, J.: The effect of sinusoidal streching upon the activity of stretch receptors in voluntary muscle and their reflex responses. J. Physiol., 144: 373386, London, 1958. 